University of Nebraska - Lincoln

DigitalCommons@University of Nebraska - Lincoln

Faculty Publications, Department of Psychology

Psychology, Department of

3-2011

\title{
The traumatic stress response in child maltreatment and resultant neuropsychological effects
}

\author{
Kathryn R. Wilson \\ Mary Free Bed Rehabilitation Hospital, Grand Rapids, MI, wilson.kate@gmail.com \\ David J. Hansen \\ University of Nebraska-Lincoln, dhansen1@unl.edu \\ Ming Li \\ University of Nebraska-Lincoln, mli2@unl.edu
}

Follow this and additional works at: https://digitalcommons.unl.edu/psychfacpub

Part of the Psychiatry and Psychology Commons

Wilson, Kathryn R.; Hansen, David J.; and Li, Ming, "The traumatic stress response in child maltreatment and resultant neuropsychological effects" (2011). Faculty Publications, Department of Psychology. 549. https://digitalcommons.unl.edu/psychfacpub/549

This Article is brought to you for free and open access by the Psychology, Department of at DigitalCommons@University of Nebraska - Lincoln. It has been accepted for inclusion in Faculty Publications, Department of Psychology by an authorized administrator of DigitalCommons@University of Nebraska - Lincoln. 


\title{
The traumatic stress response in child maltreatment and resultant neuropsychological effects
}

\author{
Kathryn R. Wilson, David J. Hansen, and Ming Li \\ University of Nebraska-Lincoln, Lincoln, NE, United States \\ Corresponding author — K. R. Wilson, Department of Psychology, Mary Free Bed Rehabilitation Hospital, \\ 235 Wealthy Street SE, Grand Rapids, MI 49503, USA; email wilson.kate@gmail.com
}

\begin{abstract}
Child maltreatment is a pervasive problem in our society that has long-term detrimental consequences to the development of the affected child such as future brain growth and functioning. In this paper, we surveyed empirical evidence on the neuropsychological effects of child maltreatment, with a special emphasis on emotional, behavioral, and cognitive process-response difficulties experienced by maltreated children. The alteration of the biochemical stress response system in the brain that changes an individual's ability to respond efficiently and efficaciously to future stressors is conceptualized as the traumatic stress response. Vulnerable brain regions include the hypothalamic-pituitary-adrenal axis, the amygdala, the hippocampus, and prefrontal cortex and are linked to children's compromised ability to process both emotionally-laden and neutral stimuli in the future. It is suggested that information must be garnered from varied literatures to conceptualize a research framework for the traumatic stress response in maltreated children. This research framework suggests an altered developmental trajectory of information processing and emotional dysregulation, though much debate still exists surrounding the correlational nature of empirical studies, the potential of resiliency following childhood trauma, and the extent to which early interventions may facilitate recovery.
\end{abstract}

Keywords: child abuse, neuropsychology, emotional trauma

\section{Contents}

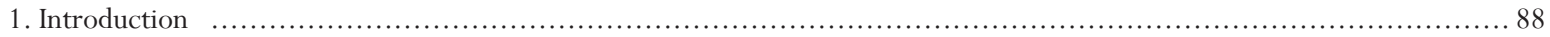

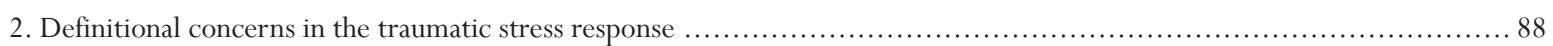

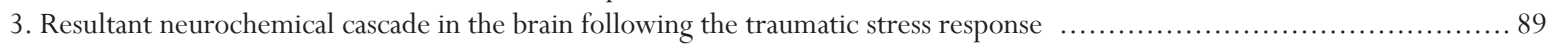

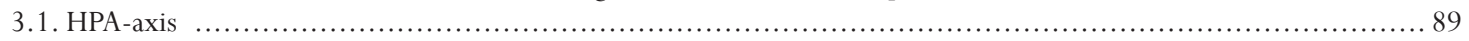

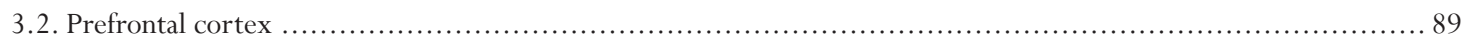

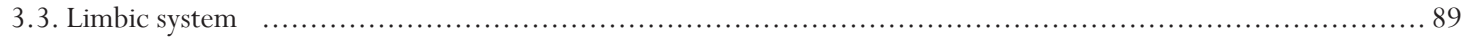

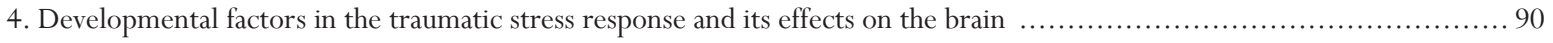

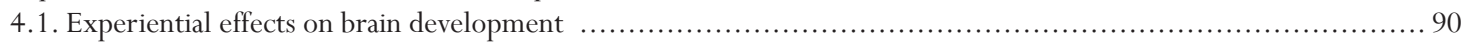

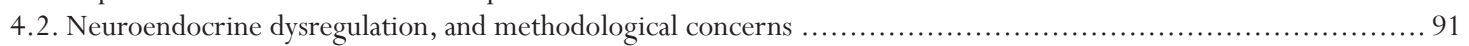

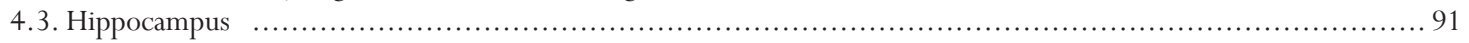

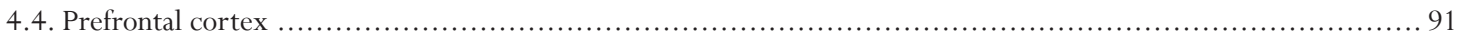

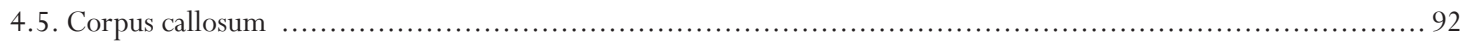

5. Clinical presentation of the traumatic stress response following child maltreatment ................................ 92

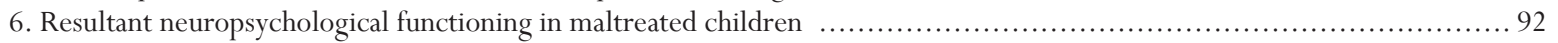

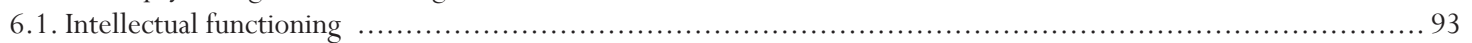

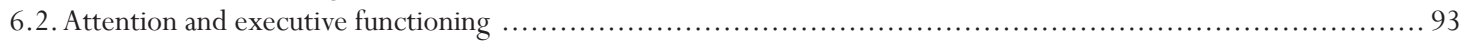

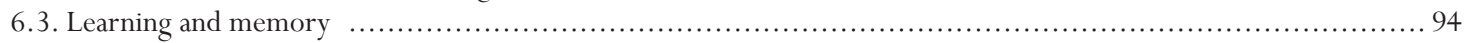

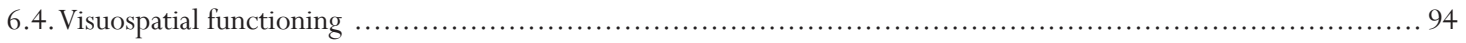

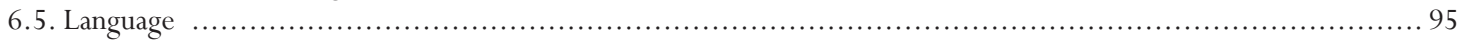

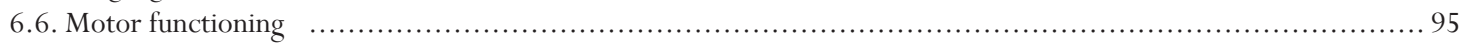

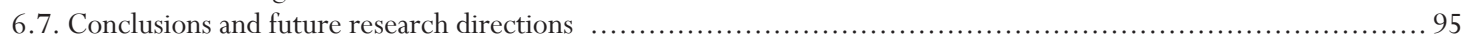

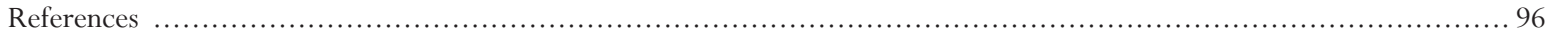




\section{Introduction}

Child maltreatment is recognized as a widespread and pervasive problem in the United States. The U.S. Department of Health and $\mathrm{Hu}-$ man Services (2007) reported 896,000 cases of substantiated maltreatment in 2005 alone. Clinicians, researchers and the general public share a common concern regarding the child victims of maltreatment. There is a dearth of literature on child maltreatment that supports the salience of preventative measures, effective interventions, and access to services for recovery from maltreatment. Despite the breadth and depth of information regarding child maltreatment, researchers are still exploring the vicissitudes of maltreatment in our society.

Child maltreatment occurs in several different forms. U.S. Department of Health and Human Services, Administration on Children, Youth and Families (2007) defines the different forms of child maltreatment within a commission-omission paradigm. Physical and sexual abuse are acts of commission of excessive physical punishment and inappropriate sexual contact with a child, respectively, whereas neglect is an act of omission, with harmful effects resulting from the lack of a caregiver's actions for a child's welfare (DHHS, 2007). Exposure to domestic violence diverges from the commission-omission definitional schema for child maltreatment in that the action is directed to someone other than the child, but is nonetheless resultantly harmful to the child's welfare (Fantuzzo \& Mohr, 1999). Furthermore, it is also common for children to experience multiple forms of maltreatment (Carter, Weithorn, \& Behrman, 1999; Hulme \& Agrawal, 2004). In community studies, other researchers note a significant percentage of their samples to have experienced multiple forms of abuse (Bifulco, Moran, Baines, Bunn, \& Stanford, 2002; Silverman, Reinherz, \& Giaconia, 1996). Several researchers highlight the need for more explicit descriptions of maltreatment in research studies (e.g., Manly, 2005). With such a variety of definitional schema in the literature, many researchers are calling for and developing classification systems for child maltreatment (e.g., Cicchetti, 2007). For these reasons, it is important to approach maltreatment from the unifying definition of an experience outside the average expectable environment that has the potential to harm a child.

Maltreatment has a variety of effects. Some children experience short-term problems immediately following their maltreatment, while others go on to have pervasive problems for months or even years (e.g., Kendall-Tackett, Williams, \& Finkelhor, 1993). Fortunately, there is also a percentage of resilient children that do not exhibit observable maladaptive effects to maltreatment (e.g., Cicchetti, 2007). Children that do experience difficulties after enduring maltreatment may display one or several different types of problems. These types of problems can range from externalizing problems (i.e., conduct problems, aggression, and risky sexual behavior), to internalizing problems (i.e., depression, self-harm, and suicidality). Similarly, researchers estimate that $20-63 \%$ of maltreated children have an extremely aversive response and develop Posttraumatic Stress Disorder (Gabbay, Oatis, Silva, \& Hisrch, 2004). While these behaviors may result from many different experiences, when the behavior is clearly preceded by child maltreatment it can be inferred that the stress of the maltreatment experience was causally involved in the behavioral response.

There has been increasing attention to the traumatic stress response. Major contributions have been made in recent years to the child maltreatment literature base by psychiatrists, clinical psychologists, and neuropsychologists utilizing this framework. The strength of this approach is that it allows different fields to synthesize findings from different populations and methodologies under a common philosophy to work towards understanding the common problem of child maltreatment. Further, a unifying philosophy can orient research in the field without impingement of DSM criteria on methodological design. With such a breadth of research contributions, there is also great depth added to the field. Clinical psychology has provided much thus far in terms of research on the individual psychological effects of child maltreatment (e.g., Cicchetti \& Toth, 2005). Similarly, much has been offered on the biochemical, brain structural, and physiological effects of maltreatment through neuroimaging work (e.g., Bremner et al., 2003; De Bellis, 2005; Teicher, 2002). Neuropsychology has afforded the opportunity to enhance our understanding of the brain-behavior relationship by systematically testing individuals' functional capacities that are hypothesized to be affected from the neuroimaging literature (e.g., Liberzon \& Martis, 2006; Shin, Rauch, \& Pitman, 2006). And finally, animal studies allow for more experimental rigor and more direct examination of the casual effects of maltreatment than clinical studies (e.g., Cohen \& Zohar, 2004; Harvey, Brand, Jeeva, \& Stein, 2006)

Cicchetti and Lynch (1993) offer one of the most widely accepted frameworks for understanding the intricacies of child maltreatment. Their ecological-translational model accounts for the dynamic childenvironment relationship within a developmental framework. Child maltreatment is viewed as an adversity outside the realm of the average expectable environment. When a child is maltreated, her or his developmental trajectory is altered. This altered trajectory has innumerable costs (Cicchetti, 2007). These costs range from the immediate individual effects, such as medical bills and the cost of therapeutic services for victims and perpetrators, to the long term effects such as court costs of legal proceedings. Also important are the less tangible and more pervasive effects such as pain, suffering, and diminished quality of life for victims.

The purpose of this literature review is to elucidate how the traumatic stress response to child maltreatment affects neuropsychological functioning following psychological trauma. In order to understand the traumatic stress response on these functional abilities, it is important to review contributing areas. As it is understood that there is a systematic biochemical response to stress in the brain, psychologists need to understand the neurochemical cascade that results from a traumatic stress response (e.g., De Bellis, Hooper, \& Sapia, 2005). Thus, the neurochemical effects of the traumatic stress response are first explained from adult clinical and animal studies. Second, it is important to gain a broad understanding of general brain development in children so as to have an appreciation for what an altered developmental trajectory could affect (Glaser, 2000). Third, specific studies of the traumatic stress response to child maltreatment will be examined in the clinical literature (e.g., Cohen, Perel, De Bellis, Friedman, \& Putnam, 2002). Fourth, the biological response systems that were hypothesized to be altered by the traumatic stress response and linked to behavioral symptom response in maltreated children will be explored in terms of any manifested neuropsychological differences in functioning (e.g., Liberzon \& Martis, 2006). Finally, we point out several less explored areas that deserve future research attention and suggest approaches to address important issues in those areas, including inclusive criteria for subject recruitment, robust assessment of children's functioning, and replication of adult neuropsychological studies with children and adolescents.

\section{Definitional concerns in the traumatic stress response}

While a major trend in the literature is utilization of a traumatic stress response framework, researchers use different working definitions of traumatic stress response. Much research focuses on the altered biological stress response system following trauma; and it is not uncommon to find that most stress response literature is located under the rubric of PTSD (e.g., Bevans, Cerebone, \& Overstreet, 2005; Cohen et al., 2002; De Bellis, 2005; Delahanty \& Nugent, 2006; Teicher et al., 2003). This pathology focused approach allows for exploration of maladaptive outcomes following trauma so significant that it may permanently alter the stress response system. However, individuals are not equally affected by similar experiences. Cicchetti and Toth (2005) postulates an ecological model that encompasses a variety of moderating factors on a child's maltreatment experience that allows for exploration of a variety of stress 
responses to the trauma. His line of developmental traumatology research addresses resiliency in responding. For the purposes of this review, a traumatic stress response (TSR) is defined as an alteration in the neurochemical cascade that usually acts to respond to psychological stress by preserving homeostasis and allowing for continuation along the developmental trajectory provided by the average expectable environment. Thus, there are many possible responses to the traumatic stress of child maltreatment. For individuals whose neuropsychological functioning is altered, the hypothesized link between their altered functioning and maltreatment experience is an altered neurochemical cascade (i.e., the traumatic stress response).

\section{Resultant neurochemical cascade in the brain following the traumatic stress response}

When individuals encounter a traumatic event they may respond to that trauma in a variety of ways. Cognitively, they are aware of threats to their integrity, safety, and well-being. Emotionally, they may experience intense feelings. Physically, they may notice their increased autonomic arousal. Behaviorally, they may respond passively (e.g., accepting the experience and blaming themselves) or actively (e.g., fighting with others). All of these responses are related to each other and the trauma through an intricate neurochemical feedback system that is designed to respond to threats against an individual's safety and preserve the internal and external integrity of the individual. When this system faces a stressor so acutely traumatic or so chronic in nature that the stress response system itself is altered, the individual now experiences a traumatic stress response.

The traumatic stress response begins with an assessment of threat that serves to activate a cascade of neurochemical events to help the individual respond to that stressor and return the internal homeostasis (Bevans et al., 2005). The traumatic stress response differs from the regular stress response in that the neurochemical cascade outlives the threat of the original stressor, causing disruption of homeostasis (Weber \& Reynolds, 2004). The structural and functional capacities of the brain are then locked into a maladaptive feedback cycle (Southwick, Rasmusson, Barron, \& Arnsten, 2005). This cycle directly affects brain regions involved in the stress response system, regions that are influenced by the stress response system regions, and any developing brain areas that may be sensitive to neurochemical dysregulation (Cohen et al., 2002; Vermetten \& Bremner, 2002a, b).

Researchers differ between which brain regions are included in their models of the traumatic stress response. For example, Heim and Nemeroff (2001) outline the corticotrophin releasing factor neurotransmission effects on the hypothalamus, hippocampus, and autonomic nervous system in their working model. Disseth (2005) includes the hypothalamuspituitary-adrenal axis, the sympathetic and parasympathetic nervous systems, and glucocorticoid effects in his broad approach to the traumatic stress response model. De Bellis (2005) describes the traumatic stress response to include the hypothalamus- pituitary-adrenal axis, thalamus, amygdala, and hippocampus. Logically, there is considerable overlap between models due to the genetically predetermined stress response. The human body is intricately interconnected, with alterations from the traumatic stress response theoretically leaving all other systems susceptible to dysregulation as well. However, there is also variability between models as based on which chain reaction of events is examined. Most researchers agree that the traumatic stress response is a neurochemical cascade that involves neurotransmitter activation of the hypothalamic-pituitary-adrenal axis, the prefrontal cortex, and the limbic system.

\subsection{HPA-axis}

The hypothalamus-pituitary-adrenal axis (HPA-axis) is a system that is central to the stress response. The main function of the HPA-axis is to assess threat, trigger a neuroendocrine cascade to initiate behavior response, and to terminate that cascade with the cessation of the threat (Bevans et al., 2005). These actions are done primarily through increasing cortisol production, suppressing the immune system, increasing stimulatory glucose and lowering the fear response to avoid overreaction of these responses to preserve homeostasis (Disseth, 2005).

The hypothalamus is both part of the limbic system and the HPA-axis. Researchers differ as to whether it is included in discussion of the limbic system, the HPA-axis or both. Here it is discussed within the HPA-axis as it is central to its functioning, and so as to prevent redundancy of discussion in other sections.

The neuroendocrine cascade in the HPA-axis begins with stimulation of the hypothalamus from increased catacholamines following a stressor. When stimulated, the hypothalamus secretes corticotrophin-releasingfactor (CRF) (Vermetten \& Bremner, 2002a, b). CRF is integral to the stress response as it affects brain functioning in several ways. It facilitates brain functioning by increasing arousal, alertness, attention, and readiness, which can combine to create anxiety-like behavior (Vermetten \& Bremner, 2002a, 2002b). CRF from the hypothalamus also serves to stimulate the pituitary to produce ACTH. Pituitary ACTH then stimulates the adrenal glands to produce the glucocorticoids cortisol and corticosterone. Of these two glucocorticoids, cortisol serves to initiate the behavior response (Disseth, 2005).

The HPA-axis functions in response to stressors and should stop cortisol production when the stressor is removed. One of the major means of detecting HPA-axis dysregulation is through cortisol changes. There is a natural diurnal fluctuation in cortisol and a natural cortisol increase when threat is assessed (Bevans et al., 2005). When there is a lack of diurnal fluctuation in cortisol or over-responsiveness or under-responsiveness to challenge, it is inferred that the HPA-axis is not managing cortisol appropriately (Cohen et al., 2002; Disseth, 2005). In addition to the effects of cortisol, the HPA-axis functioning has a reciprocal relationship with the prefrontal cortex, which is described below (Teicher et al., 2003).

\subsection{Prefrontal cortex}

The main function of the prefrontal cortex (PFC) with regards to the traumatic stress response is to control attention, working memory, sort out sensory input for relevant information, and regulate inhibitory response (Weber \& Reynolds, 2004). A healthy PFC functions to attend to threat and activate other brain regions to respond to threat. When the threat is removed or resolved, the PFC neurons stop sending excitatory neurotransmission to the other brain regions, such as the HPA-axis. Thus, the PFC is the shut-off valve for the stress response in the HPA-axis. In order to serve this function, the PFC must be functioning properly.

The PFC has a high concentration of dopamine receptors and its functioning is susceptible to the functioning of these receptors. Excessive dopamine can cause dysregulation by blocking excitatory glutamate, enhancing inhibitory GABA, and thus causing the PFC hyporesponsiveness. This hyporesponsiveness translates to a lack of inhibitory communication to other brain regions such as a failure to stop the fear response in the HPA-axis (Cohen et al., 2002), failure to inhibit the amygdala from assigning emotional valence to sensory stimuli, and a failure to inhibit the hippocampus (Liberzon \& Martis, 2006; Shin et al., 2006). Clinically, the medial PFC has been observed to be smaller in adults with PTSD and hyporesponsive during symptomatic states and their performance of emotionally valenced cognitive tasks (Shin et al., 2006).

\subsection{Limbic system}

Another brain region that is of major focus in the traumatic stress response is the limbic system. The limbic system consists of the thalamus, 
hypothalamus, amygdala, and hippocampus. It is often considered the emotional control center of the brain. Threat stimulates the locus coeruleus to produce noradrenaline, which is the main stimulatory neurotransmitter of the limbic system(Vermetten \& Bremner, 2002a, b). When an individual experiences a situation that can induce the neurochemical cascade of the traumatic stress response, such as child abuse, the limbic system is directly affected. Of the areas of the limbic system affected by the traumatic stress response, there is a dearth of literature discussing the effects on the amygdala, hippocampus, and hypothalamus (which was discussed in the aforementioned section on the HPA-axis).

One main function of the amygdala in the stress response system is to receive sensory input and assign emotional valence to the stimuli to engage a behavioral response to the threat. It is demonstrated that the amygdala may accomplish this by balancing glutamate-induced excitation with GABA-mediated inhibition to regulate the anxiety response (Shekhar, Truitt, Rainnie, \& Sajdyk, 2005). First, stress stimulates the amygdala to produce corticotrophin-releasing factor (CRF). Then CRF serves to engage the autonomic and behavioral response systems (Weber \& Reynolds, 2004).

When the amygdala is functioning properly, it works in conjunction with the hippocampus to encode emotional valence to memories to activate a defensive response when the threat is re-encountered. However, under extreme traumatic stress, the amygdala becomes sensitive to "kindling" effects, and assigns emotional valence to nonthreatening stimuli (e.g., memories). Kindling resembles seizure-like behavior neurologically (Teicher et al., 2003) and is described clinically as dissociative symptoms (Disseth, 2005). It is hypothesized that kindling in the amygdala leads to eventual hyperarousal and diminished behavior inhibition. Thus the traumatic stress response dysregulates the amygdala to assign emotional valence to nonthreatening stimuli and invoking unnecessary behavioral priming (Cohen et al., 2002; Shin et al., 2006).

Animal researchers have highlighted the interplay of the amygdala and other brain regions in emotional memory. A review of the animal literature by Phelps (2004) highlights the importance of the amygdala in emotional memory encoding such that the amygdala assigns emotional valence and directs hippocampal encoding of stimuli. This review also explains that the amygdala can trigger physiological arousal with emotional stimuli even if the physiological arousal was not experienced at encoding. Another review by Delgado, Olsson, and Phelps (2006) concludes that the amygdala is involved in all stages of fear learning and prefrontal areas during extinction of fear. Thus, the amygdala works with the hippocampus in encoding emotional memories, the prefrontal cortex in extinction of fear associated with emotional memories, and directs emotional valence of memories in general.

As mentioned previously, the hippocampus is involved in encoding memories, among other functions. The hippocampus is composed of a high level of glucocorticoid receptors. These receptors are excited by cortisol, the major stress-response hormone, and are thus susceptible to the excitotoxic effects of cortisol through neuronal degradation (e.g., Harvey, Bothman, Nel, Wegener, \& Stein, 2005; Harvey, Oosthuizen, Brand, Wegner, \& Stein, 2004; Harvey et al., 2006; Shin et al., 2006). Most stressors produce increased cortisol levels that excite the glucocorticoid receptors in a manner that adaptively responds to the stressor. When an individual experiences an acutely traumatic or chronic stressor, part of the traumatic stress response entails elevating cortisol levels to the point of burning out the hippocampal neurons by over stimulation of the glucocorticoid receptors. When neurons are burned out, all connected neurons suffer damage from the loss of connection. Neurogenesis along preformed pathways is also diminished by the loss of the neurons that lead the pathway. The neurotoxic effects of a dysregulated hippocampus are not readily evident as it takes time to quantify noticeable differences in cell density. This is especially difficult in the hippocampus as neurogenesis occurs into the third decade of life and may mask any initial cell loss (Teicher, Tomodoa, \& Andersen, 2006).
Thus, in adult humans and studies with animals, there is a neurochemical cascade of events in the brain that follows exposure to stress. This stress response system is altered when the stressor is perceived as a serious threat to the integrity of the individual. This traumatic stress response affects many different regions of the brain including, but not limited to, the HPA-axis, the prefrontal cortex (PFC), and the limbic system. Following traumatic stress, the HPA-axis does not produce cortisol in response to subsequent stressors to the same extent or in the same direction as previously demonstrated (Cohen et al., 2002; Linkowski, 2003). The PFC which, normally serves to regulate the neuroendocrine cascade triggered by the HPA-axis, is dysregulated by traumatic stress such that it cannot properly assess for threat and provide neurofeedback to regulate the HPA-axis response (Liberzon \& Martis, 2006; Shin et al., 2006). To further exacerbate the dysregulated stress response system, the limbic system encodes emotional valence to disorganized sensory and visual memories such that individuals are primed to misperceive threat and engage their maladaptive stress response system.

In summary, individuals are primed to misperceive threat, be overly emotionally response, ineffectually cognitively responsive, and present disorganized or maladaptive behavior responses to perceived threats following exposure to traumatic stress that has altered the neurochemical cascade response to stress.

\section{Developmental factors in the traumatic stress response and its effects on the brain}

While the traumatic stress response is relatively well-understood in mature animals, the contributions of developmental factors are just beginning to be explored. Individuals of a given species are born with most of the brain structures that will be present at maturity; yet, functioning varies greatly across the life span. In terms of the traumatic stress response, there are many areas in the early stages of exploration. First, developmental research has demonstrated how brain growth and maturation has a reciprocal relationship with the environment. Second, trauma research has compared functional differences in regions researched in adults. Third, functional differences have been observed in regions not found to be affected in adults. Once these bodies of research are understood, one can begin to conjecture how measured neuropsychological differences following trauma in children are related to the neurochemical cascade of the traumatic stress response within a developmental framework.

\subsection{Experiential effects on brain development}

Normal brain development occurs within the average expectable environment. Experiences that are expected for normal brain development, such as neuronal overproduction, synaptic pruning, and myelination, are logically referred to as experience-expectant developmental phenomena (Greenough, Black, \& Wallace, 1987). Subsequently, experiences that shape brain development but are not needed for the development to occur are referred to as experience-dependent phenomena. In terms of maltreatment, the effects are deleterious on development when experience-expectant experiences are prevented or experience-dependent experiences alter the developmental trajectory.

As a child's brain grows and develops, there are "sensitive periods" of development in which outside influences affect the brain's ability to develop certain capacities in the future. This may occur by either prevention of experience-expectant or incursion of experience-dependent phenomena. Deprivation of needed experiences for proper child development is neglect in approximation and definition (e.g., De Bellis, 2005). Heim and Nemeroff (2001) relay that neglect places children in a state of heightened stress from missing experience-expectant developmental experiences of caregiver enrichment, resulting in cognitive and emotional deficits. Ford (2005) and Weber and Reynolds (2004) cite 
physical abuse as a type of experience that alters experience-dependent development when a child does not receive the reciprocal reinforcement of learning from interactions with caregivers in the average expectable environment. Cohen et al. (2002) postulate that a sudden onset of abuse in a previously nurturing relationship can be particularly traumatic to children. Such acute stress from experience-dependent experiences can alter a child's developmental trajectory through the traumatic stress response (Cicchetti, 2007).

\subsection{Neuroendocrine dysregulation, and methodological concerns}

Research with traumatized children differs from research with adults in that studies with child samples tend to utilize mixed methods of salivary assays of cortisol and social, emotional, behavioral, and cognitive psychological assessments to allow for less intrusive exploration of neurochemical dysregulation and provides corollary individual functional information. Cortisol has been studied extensively with anxiety, depression, and the traumatic stress response because it is easy to sample and a key element reflecting the functioning of the HPA axis and limbic system. In adults, lowered cortisol levels are correlated with exacerbated PTSD symptoms (e.g., Altemus, Dhabhar, \& Yang, 2006). In children, the direction of cortisol dysregulation has not been as uniform across studies, though it is generally accepted that it is dysregulated. Although only a handful of studies have been conducted in this area thus far, research indicates altered levels of cortisol at both morning and afternoon sampling times for maltreated children as well as an alteration in the expected amount of decrease from morning to afternoon cortisol as is found with natural circadian rhythm, as described below.

In one example of altered cortisol following maltreatment, Delahanty, Nugent, Christopher, and Walsh (2005) sampled 82 children (ages 8-18) $12 \mathrm{~h}$ after admission to a hospital trauma unit and found children's cortisol to be higher after trauma ("usually abuse or maltreatment") and cortisol levels correlated with PTSD symptoms severity and duration. King, Mandansky, King, Fletcher, and Brewer (2001) recruited a community sample of 10 sexually abused girls (ages 5-7) from the Department of Social Services and found lower morning cortisol compared to 10 non-abused controls. Dozier et al. (2006) sampled 55 foster children (ages 20-60 months) who had experienced a variety of types of maltreatment, but who were all arguably stressed by frequent placement changes within the foster care system, and found higher morning and lower evening cortisol than 104 "comparison children."

Several other studies of altered cortisol following maltreatment have been conducted with school-aged children within the context of a summer day camp. Hart, Gunnar, and Cicchetti (1996) sampled cortisol levels and depression in 131 maltreated "school-aged" children and 66 nonmaltreated children. They found depressed, maltreated children had lower morning cortisol levels when compared to non-depressed, maltreated children and showed a rise in afternoon cortisol levels. Cicchetti and Rogosch (2001a) sampled cortisol levels and psychopathology (internalizing and externalizing) of 167 maltreated and 204 non-maltreated "school-aged" children at a day camp and found that maltreatment serves as a moderator of the impact of internalizing problems on cortisol regulation. In a later expansion of the previous study, Cicchetti and Rogosch (2001b) also found that cortisol dysregulation patterns were specific to the type of maltreatment experienced. Maltreated children who had been physically and sexually abused exhibited higher morning cortisol levels, whereas children who had only been physically abused showed a lower level of morning cortisol and had a smaller decrease from morning to afternoon cortisol.

It is hypothesized by several researchers that cortisol dysregulation in children following maltreatment is dependent on the nature of the maltreatment as it evokes the initial traumatic stress response, but then is also shaped by the neurotoxic effects of heightened cortisol on developing brain regions during their sensitive periods (e.g., Weber \& Reynolds,
2004). In particular, researchers describe the hippocampus, prefrontal cortex, and corpus callosum as being vulnerable to neuroendocrine dysregulation from the traumatic stress response in maltreated children.

\subsection{Hippocampus}

One of the brain regions that is particularly susceptible to the neurotoxic effects of increased cortisol is the hippocampus (Heim \& Nemeroff, 2001). Several studies have examined hippocampal volume following trauma in both children and adults and have reported reduction in hippocampal volume. Bremner et al. (2003) sampled 10 women with childhood sexual abuse and current PTSD, 12 women with childhood sexual abuse and no PTSD, and 11 women without childhood sexual abuse or PTSD. A reduction in hippocampal volume was found in women with a childhood sexual abuse history and PTSD compared to both other groups. Bonne et al. (2001) sampled 37 trauma survivors' hippocampal volume one week and six months post trauma, at which time they also assessed for PTSD. Ten subjects were determined to have PTSD at six months, but did not demonstrate any reduction in hippocampal volume compared to their earlier measured hippocampal volume nor the hippocampal volume of those who did not develop PTSD. De Bellis, Hall, Boring, Frustaci, and Moritz (2001) measured the hippocampal volumes of nine pre-pubertal maltreated subjects with maltreatment-related PTSD and nine matched non-maltreated control subjects at baseline and after two years. There was no difference found between groups' hippocampal volume at baseline, followup, or across time. Thus there appears to be a latent effect of the increased cortisol on hippocampal volume reduction.

The latent effects of hippocampal volume reduction can be explained, at least in part, by a difference in the populations sampled. The early identification, intervention, and treatment of maltreated children who are sampled do not continue to experience the chronic stress that results from unidentified and/or untreated maltreated children. Further, children who are maltreated during childhood are susceptible to the benefits and detriments of the effects of cortisol on a hippocampus that is in a sensitive period for development. De Bellis et al. (2001) relate that the hippocampus is still experiencing a high rate of neurogenesis during childhood that may mask initial cell loss as well as enabling volume reduction to be overcome if maltreatment is stopped during this sensitive period. Teicher et al. (2003) further explained the differences found between prepubertal and peripubertal children's literature of maltreatment-related hippocampal reduction to the fact that peripubertal children are past the point of increased neurogenesis and into a period of synaptic pruning. Thus, maltreatment experienced by peripubertal children is considered to be more detrimental to hippocampal volume than maltreatment experienced by prepubertal or postpubertal children. Teicher et al. (2004) also noted different sensitive periods of hippocampal myelination by age and gender. The window of vulnerability for reduced myelination is earlier for boys and later for girls. This correlates with findings of reduced hippocampal volume in neglected boys (which is more likely to occur at an earlier age) and sexually abused girls (which is more likely to occur at a later age). In Teicher et al.'s (2006) more recent work he described earlier child sexual abuse to be related to reduced hippocampal volume, while later child sexual abuse is related to decreased prefrontal cortex volume; a difference he attributes to the different sensitive periods of the different brain regions. Thus, reduced hippocampal volume is hypothesized to result from the excitotoxic effects of cortisol on the hippocampus during its sensitive period of development in early childhood.

\subsection{Prefrontal cortex}

The prefrontal cortex continues to develop into early adulthood and thus has an extended sensitive period. Reichert, Carrion, 
Karchemshkiy, and Reiss (2006) compared 23 children (ages 7-14) with a history of "interpersonal trauma" and PTSD symptoms to a sample of 24 "age-equivalent, healthy" children. They found differences in prefrontal cortex grey matter volume in children with PTSD resulting from "interpersonal trauma." One reason that executive functioning abilities, such as planning and controlling behavioral responses, are thought to be affected by traumatic stress is that both are linked to prefrontal cortical functioning. Aberrations in prefrontal cortex size and/or functioning have been related both to traumatic experiences and poorer executive functioning. This area of the brain is rapidly developing during childhood, more susceptible to insult (i.e., traumatic stress), and its development effects future executive functioning capacity. Thus dysregulation in developing such capacities during childhood (e.g., learned helplessness from maltreatment experiences) have greater impact in how children will handle such situations in the future. It has also been hypothesized that as children gain a greater sense of self, they are more prone to depression following cognitive appraisal of their maltreatment experiences. Development of such cognitive appraisal abilities are also developed later in childhood and adolescence during a sensitive period of the prefrontal cortex.

\subsection{Corpus callosum}

A third area that has been found to be particularly susceptible to the effects of maltreatment is the corpus callosum. The corpus callosum is the area connecting the two hemispheres of the brain. Its integrity is important for effective communication across the brain and integration of brain functions. Although the corpus callosum is not a structure regularly included in the discussion of the traumatic stress response in adults, there is a substantial body of literature linking the effects of maltreatment during sensitive periods of brain maturation to differences in the structure and function of the corpus callosum. When there is a reduction in size of the corpus callosum, there is potential for lateralization of functioning such that one side of the brain may be unusually taxed when an individual is trying to complete tasks (Weber \& Reynolds, 2004).

In maltreated children and primates, researchers have found reduction in corpus callosum size following maltreatment (e.g., Teicher et al., 2006). Cohen et al. (2002) linked duration of maltreatment to corpus callosum size and IQ in their review of the literature. Teicher et al. (2004) sampled 115 children who were admitted consecutively to a large hospital. Of this sample, 51 were admitted for psychiatric reasons, and 28 of these children had a history of maltreatment. Corpus callosum size differences were found to be gender and maltreatment specific. $\mathrm{Ne}-$ glect was found to have the greatest reduction in corpus callosum size for boys, while sexual abuse was found to have the greatest effect for girls. Teicher further relays that these effects were related to maltreatment experiences but not PTSD diagnoses or symptoms. He explains these findings by the effects of maltreatment on the corpus callosum during sensitive periods, preventing myelination (Teicher et al., 2003). A lack of myelination in the corpus callosum causes dissociative effects similar to reported experiences of temporal lobe epileptics (Teicher et al., 2006). By preventing integration of sensory stimuli by inhibiting communication between brain regions, lateralization heightens arousal in emotional reactive areas, leading to increased behavioral problems and dissociative symptoms in maltreated children (Disseth, 2005).

\section{Clinical presentation of the traumatic stress response fol- lowing child maltreatment}

There are a number of different studies that have linked children's behavioral response to trauma to neurochemical alterations that are both maladaptive and distinct from those of adults. Of particular importance are studies of neuroendocrine dysregulation seen through studies of cortisol and structural alterations found in the hippocampus, corpus callosum, prefrontal cortex, and cerebral volume as a whole. These alterations in children's brain functioning, though different from adults, are still closely linked to symptomatic presentation of the traumatic stress response that is similar to adults.

One of the most notable differences following a traumatic stress response is the altered response of the individual to emotional stimuli. Many individuals, including children, are observed clinically to have an over or under-responsiveness to emotionally laden situations following trauma. Although symptoms of hyperarousal were discussed previously in relation to the traumatic stress response, it is also important to consider the effects of the traumatic stress response on emotional numbing. From Teicher's work with children, the dissociative effects of trauma have been linked to reduced corpus callosum volume.

Other researchers have used functional imaging to explore the brain mechanisms related to dissociative experiences. By using functional imaging such as MRI and PET scans, researchers can observe the regional cerebral blood flow (rCBF) in different brain regions following sensory stimuli. Weems, Saltzman, Reiss, and Carrion (2003) measured $\mathrm{rCBF}$ and dissociative experiences in female survivors of sexual trauma. They found trauma scripts trigger dissociative experiences and simultaneously increase $\mathrm{rCBF}$ to areas of the brain associated with non-verbal patterns of recall. This finding, in conjunction with other trauma researchers' correlations between emotional numbing and symptoms of hyperarousal, avoidance, and reexperiencing, lead to hypotheses of memory disintegration (e.g., Salmon \& Bryant, 2002). Similar to Weems et al. (2003), Bremner et al. (1999) studied the $\mathrm{rCBF}$ of adult women survivors of CSA without PTSD. As they listened to trauma scripts, dysfunction was found in the medial PFC, hippocampus, and visual association cortex and increased activation in the posterior cingulated and motor cortex of women with PTSD. Frewen and Lanius (2006) explain rCBF dysregulation and dissociative symptoms through an altered stress response system that engages brain areas associated with non-verbal, bodily arousal awareness, and episodic recall of memories as similar to the behavioral immobilization strategy of animals faced with inescapable predation. Thus the initial trauma altered the stress response system such that processing of subsequent emotional stimuli is misperceived as threatening and a maladaptive response is generated.

While it can be fairly easy to decipher a clinical presentation of dysregulated emotional processing from trauma history, the dysregulated processing of neutral stimuli can be more difficult. When a trauma history is unknown for a child, the symptoms of PTSD in children can be easily misinterpreted as behavior dysregulation, cognitive deficits, or ADHD. Several researchers point to the potential misdiagnosis of ADHD in maltreated children (e.g., Cook-Cotton, 2004; Disseth, 2005; Ford, 2005; Salmon \& Bryant, 2002; Weber \& Reynolds, 2004). Other researchers hypothesize that the traumatic stress response following child maltreatment will not only affect emotional functioning, but cognitive and neuropsychological functioning in school and on a broader basis (Cook-Cotton, 2004; Danckwerts \& Leathem, 2003; De Bellis, 2005; Horner \& Hamner, 2002).

\section{Resultant neuropsychological functioning in maltreated children}

As mentioned previously, there are a number of potential implications of the traumatic stress response on a maltreated child's functioning. The neurochemical cascade of the traumatic stress response during sensitive periods of development for children can alter the developmental trajectory of children's emotional, behavioral and cognitive development. In particular, the hippocampus and prefrontal cortex are key structures involved in children's cognitive development that are affected by the traumatic stress response. Cell loss and delays 
in myelination cause structural damage that may lead to functional deficits in memory and spatial processing, and attention and executive functioning, in the hippocampus and prefrontal cortex, respectively. As with other effects of traumatic stress on emotional and behavioral development, alterations in cognitive processing, particularly during critical periods of development, can alter the cognitive developmental trajectory such that there is potential for delayed cognitive development (e.g., Cicchetti, 2007; Watts-English, Fortson, Gibler, Hooper, \& De Bellis, 2006). Thus, there is an imperative need for research on the effects of the traumatic stress response on the cognitive development, development of information processing, and neuropsychological functioning of children.

Much research has been done on the effects of the traumatic stress response on the neuropsychological functioning in adults. Most of this research has been conducted within a PTSD framework, but is applicable for this review through the universality of the traumatic stress response framework as both are based on the same cascade of neurochemical events. Although some differences have been noted in the traumatic stress response between children and adults (e.g., direction of cortisol dysregulation) the affected brain regions and functions are similar. Thus an exploration of the neuropsychological effects of the traumatic stress response can be examined in a manner similar to that which has been done with adults, including a review of the literature by neuropsychological functional domains. It is important to cover all functional domains whether or not there is hypothetical support for effects in those domains as sound research must explore confirmatory and disconfirmatory evidence. Covering all functional domains will also give a more complete picture of the breadth of maltreatment effects that can be compared to adult findings and the hypothesized findings for children. As such, the neuropsychological functioning within the domains of intellectual functioning and scholastic achievement, attention and executive functioning, learning and memory, visuospatial processing, language, and motor functioning will be reviewed (e.g., Danckwerts \& Leathem, 2003; De Bellis et al., 2005). Within each section the findings of the adult literature will be reviewed followed by a discussion of the findings of the child literature, if any.

\subsection{Intellectual functioning}

Intellectual functioning and academic achievement in this review will be defined as general cognitive ability and achieved academic ability, respectively, as measured by standardized assessments. Intellectual functioning in the trauma literature is generally measured by IQ scores. Academic achievement in the trauma literature is usually measured by scholastic performance (i.e., grades). While IQ has been measured in both the adult and child literature, academic achievement has received no attention in the adult literature, predominantly due to the fact that most adults are not still in school. In the adult literature, there have been several studies of IQ scores measured in adults who present clinically with PTSD. In general, a PTSD diagnosis has been correlated with lower full scale IQ scores in adults. This includes studies of with populations of combat veterans, adult rape victims, and adult survivors of child sexual abuse (Brandes et al., 2002; Gil, Calev, \& Greenberg, 1990; Gurvits, Lasko, \& Schachter, 1993; Macklin et al., 1998; Vasterling, Brailey, Constans, Borges, \& Sutker, 1997, Vasterling et al., 2002). Two researcher groups, Gil et al. (1990) and Vasterling et al. (1997) have explored the differences between composite scores on IQ tests to finds that Verbal IQ Composite scores tend to be lower on both fluid and crystallized tasks. IQ remained correlated with PTSD diagnosis even when combat exposure was controlled for statistically in veterans (Macklin et al., 1998; McNally \& Shin, 1995; Vasterling et al., 2002). Despite some statistical controls, a debate remains as to whether lower IQ was a result of PTSD and trauma exposure, or if it was a risk factor for developing PTSD following trauma exposure.
In children, fewer studies have been conducted, but findings have been similar to that of the adult literature. In a study by Jones, Trudinger, and Crawford (2004) children who were referred for sexual abuse investigations were found to show academic underachievement and intellectual impairment. Using standardized assessment measures (e.g., WPPSI, WISC-III, and WIAT) the intelligence and achievement performance of a group of 21 sexually abused children was found to have higher than average percentage of "impaired" individuals compared to the population. It is hypothesized that this may be due to lack of parental concern with their children's welfare both physically and academically as these children were receiving less academic support than they needed as determined by their performance. Further, it was shown that these children tended to be underserved and were receiving less academic supports than nonabused children. Similarly, a sample of child and adolescent inpatients with PTSD were found to have decreased verbal IQ scores in comparison to non-traumatized and traumatized, non-PTSD inpatients (Saigh, Yasik, Oberfield, Halamandaris, \& Bremner, 2006). Within a different sample of child psychiatric inpatients, children with sexual abuse histories had the lowest performance IQ scores when compared to groups of nonabused and physically abused inpatients, though the trend was non-significant for between groups comparison of abuse types (Sadeh, Hayden, McGuire, Sachs, \& Civita, 1994). A review by De Bellis (2005) summarizes the effects of neglect as leading to delayed cognitive development. Although neurobiological effects of the traumatic stress response are likely to affect cognitive capacity in children similar to that demonstrated in the adult literature, a review by Cicchetti and Toth (2005) highlight other factors that mediate this association. They explain that while cognitive ability and perceived ability mediated academic performance in maltreated children, their dissociative and destructive behaviors could affect their ability to function in the school environment to limit their scholastic success.

\subsection{Attention and executive functioning}

One of the areas most susceptible to the aversive effects of the traumatic stress response is the prefrontal cortex. The prefrontal cortex is particularly open to insult during childhood and adolescence as this region of the brain is still undergoing some neurogenesis and synaptic pruning. More importantly, childhood and adolescence is a sensitive period for myelination in the prefrontal cortex. Without developed myelination, there cannot be effective information exchange between the prefrontal cortex and other brain regions (e.g., Teicher, Andersen, Polcari, Andersen, \& Navalta 2002). Because the prefrontal cortex is already the area of the brain serving individuals with their attention, concentration, and executive functioning capacities, it is essential that this area of the brain be able to communicate and coordinate other brain functions. Further, to study other functional capacities, such as memory, it is necessary to know how well an individual can attend to information before assessing their ability to remember it (Danckwerts \& Leathem, 2003).

In the adult literature, it is generally accepted that attention and executive functioning are impaired in individuals with PTSD diagnoses (e.g., Horner \& Hamner, 2002). In a study of adult survivors of child sexual abuse, Raskin (1997) found a main effect for poorer executive functioning in women with a history of child sexual abuse, and specific effects of poorer executive functioning and working memory in women with a history of CSA and mild traumatic brain injury. Similarly, other researchers have found deficits in performance-based attention tasks in adults with PTSD (e.g., Vasterling et al., 2002).

Several researchers use the Mirsky model of attention to describe performance on different types of memory-related measures of attention (e.g., Vasterling \& Brailey, 2005). The Mirsky model conceptualizes attention into four different areas: focus-execute, sustain, shift, and encode. Individuals with PTSD have also demonstrated deficits on encoding 
or working memory (Beckham, Crawford, \& Feldman, 1998; Gil et al., 1990; Gurvits et al., 1993; Vasterling et al., 1997) and sustaining attention in continuous performance tasks (e.g., Gil et al., 1990; Jenkins, Langlais, Delis, \& Cohen, 2000; McFarlane, Weber, \& Clark, 1993; Semple et al., 1996), but not consistently throughout the literature (Golier et al., 1997; Sullivan et al., 2003; Vasterling, Rogers, \& Kaplan, 2000). On other measures of attention, no deficits were found in performance on focus-execute (Litz et al., 1996; Vasterling, Brailey, Constans, \& Sutker, 1998; Vasterling et al., 2002) or attention-shifting tasks (Barrett, Green, Morris, Giles, \& Croft, 1996; Gurvits et al., 1993; Jenkins et al., 2000; Sullivan et al., 2003; Vasterling et al., 2000).

One of the explanations given for the differences found in measure of attention and executive functioning is that attention is disrupted by cognitive intrusion (Koenen et al., 2001; Vasterling et al., 1998). Cognitive intrusion occurs when the individual's thought process is disrupted by unanticipated events. In individuals with PTSD, the exaggerated startle response is demonstrative of the effects of the traumatic stress response on an individual's ability to handle cognitive intrusions. In this manner, it is not the individual's capacity to attend that is affected, but rather their ability to handle these disruptions and continue to function effectively in response to sensory stimuli from their environment. Demonstratively, Shimamura (2002) found that prefrontal dysfunction is mitigated by imposed structure, allowing for individuals to better focus their attention on stimuli and not exert as much mental effort to sort out the stimuli to which they are supposed to attend.

In children, there have been fewer studies on the effects of the traumatic stress response on attention and executive functioning. Results in the child literature have been found to be generally similar to that of the adult literature, with maltreated children performing more poorly on measures of attention and executive functioning when compared to normative or comparison groups. In a study by Beers and DeBellis (2002), children with maltreatment-related PTSD performed more poorly on measures of attention and executive functioning (i.e., Stroop Color and Word Test, Digit Vigilance Test, Wisconsin Card Sorting Test, and Controlled Oral Word Association Test). Similarly, diminished performance on attention and concentration tasks (i.e., Test of Memory and Learning Attention/ Concentration Index) was found in a sample of sexually abused children compared to matched controls (Porter, Lawson, \& Bigler, 2005). In a review by De Bellis (2005), maltreated children and adolescents with PTSD were described as having deficits in executive functioning, abstract thinking, and everyday memory. Although the child literature has not yet explored the specific domains of attention and executive functioning to the extent of the adult literature, consistent findings in functional deficits of samples of maltreated children are reported.

\subsection{Learning and memory}

In the trauma literature, there has been much work done with the effects of memory. This is partially due to the fact that individuals who have experienced acute trauma often present with inability to remember details or important aspects of the trauma. Similarly, in the DSM-IV-TR (APA, 2003) one of the diagnostic criteria of posttraumatic stress disorder is an inability to recall important aspects of the trauma. While memory deficits surrounding the traumatic event(s) have been extensively studied elsewhere, memory deficits unrelated to trauma is a major functional domain of neuropsychology and will be discussed in this paper.

Memory and learning are very broad domains of neuropsychology. Memory is the ability to retain information, and learning can be viewed as the ability to utilize retained information. Within memory, there are several different domains, with some researchers circumscribing learning into memory. Zillmer, Spiers, and Culbertson (2008) break memory into sensory memory, short-term, and long term memory, with long-term memory further differentiated between declarative/explicit memory of semantic knowledge and episodic events and nondeclarative/implicit memories of habits and procedures. With regard to a neuropsychological view of the traumatic stress response, it is hypothesized that declarative memory and learning may be damaged when the hippocampus is damaged. Researchers have found correlations between hippocampal damage following trauma and memory deficits. For example, in a study by Bremner et al. (2003), women with PTSD following child sexual abuse had reduced hippocampal volume and decreased hippocampal activation during verbal declarative memory tasks. Hippocampal dysfunction was also found to be associated with impaired memory retrieval under both structured and unstructured tasks.

Several researchers have documented explicit memory deficits following trauma exposure unrelated to the traumatic event. Horner and Hamner (2002) found everyday memory deficits in a sample of combat veterans who had PTSD. Barrett et al. (1996) found deficits in visual and verbal list-learning short-term memory for combat veterans with PTSD and another co-morbid diagnosis. It was also noted that there was little difference (non-significant) between structured and unstructured tasks.

Some researchers argue that memory problems only partially explain differences in performance on memory tests between individuals with PTSD and those without. One of the explanations for this is that the hypervigilance associated with PTSD heightens sensitivity in individuals to pro-active and retro-active interference on initial learning (e.g., Uddo, Vasterling, Brailey, \& Sutker, 1993; Vasterling et al., 1998, 2000; Yehuda et al., 1995). Thus, PTSD is not associated with degraded retention when the initial formation is controlled for (e.g., Brandes et al., 2002; Bremner et al., 1993, 1995; Jenkins et al., 2000; Vasterling et al., 1998, 2002, 2000). With a variety of different methodologies used to assess differences in memory and learning following different traumatic experiences in different populations there is confusion within the literature as to whether true functional memory deficits have been observed following trauma. Theoretically, the traumatic stress response affects regions of brain functioning, such as the hippocampus, that could lead to functional memory deficits as have been demonstrated in the traumatic stress literature. In adults, there is still room for debate as to whether memory and learning are truly affected, or if there is dysfunction in the prefrontal cortex causing attentional and encoding deficits.

In children, there has been much less research on the effects of the traumatic stress response on memory and learning. The three studies that have measured memory in children yield contrasting results. Moradi, Neshat Doost, Taghavi, Yule, and Dalgleish (1999) found children with PTSD to have an overall poorer performance on the Rivermead Behavioral Memory Test than children without PTSD. Similarly, Yasik, Saigh, Oberfield, and Halamandaris (2007) showed children with PTSD to have poorer performance on the Wide Range Assessment of Memory and Learning General Memory, Verbal Memory, and Learning indices compared to non-traumatized children. However, Porter et al. (2005) observed no differences in memory functioning on the Test of Memory and Learning (except for attention and concentration tasks) between child sexual abuse victims and non-abused controls when controlling for socioeconomic status, IQ, and attention and concentration. Similarly, Beers and DeBellis (2002) did not find differences between children with PTSD from those without PTSD on memory test (i.e., California Verbal Learning Test for Children, Rey-Osterrieth Complex Figure recall). With such different comparison groups and such a limited amount of research, it is impossible to draw conclusive inferences on memory and learning in children following a traumatic stress response.

\subsection{Visuospatial functioning}

Visuospatial functioning refers to an individual's ability to process visually and spatially presented information. It has been hypothesized that individuals would have altered visuospatial functioning following a 
traumatic stress response due to hippocampal damage. It has been well documented that damage to the hippocampus has produced impairments in spatial processing. A question remains as to whether hippocampal damage following the traumatic stress response will lead to functional deficits in visuospatial processing. In a study by Gurvits et al. (2002) individuals with PTSD were found to have decreased performance on measures of visuospatial functioning when compared to individuals with a traumatic history and no PTSD. Other researchers could not attribute differences in visuospatial performance solely to PTSD (e.g., Sullivan et al., 2003). Beers and DeBellis (2002) found no differences between the visuospatial functioning of maltreated children with PTSD and socio-demographically matched, non-maltreated controls on the Rey-Osterrieth Complex Figure copy, Road Money map, Judgment of Line Orientation, or Wisc-III Block Design and Object Assembly subtests. Thus, there is little and inconclusive evidence on the effects of visuospatial performance in adults following traumatic stress, and the one study published with child sample found no differences in visuospatial functioning following traumatic stress.

\subsection{Language}

Language functioning refers to an individual's ability to process and generate verbally presented information. Although there are no hypothesized effects of the traumatic stress response on language, researching functional capacities that are not hypothesized to be effected allows for exploration of discriminant validity of the traumatic stress response. Gurvits et al. (1993) lends to the discriminant validity of the traumatic stress response with negative findings for dysgraphia and dysphasia following trauma in veterans. Most other researchers have found functional differences in language following trauma, though these are often attributed to other functional impairments. PTSD has been associated with performance decrements in word generation tasks for providing words that begin with a target letter (Bustamante, Mellman, \& David, 2001; Gil et al., 1990; Koenen et al., 2001). There have been mixed results with categorical word generation tasks (Gil et al., 1990; Uddo et al., 1993). Shimamura (2002) caution that word-list generation tasks are sensitive to memory loss and prefrontal cortical dysfunction, a functional capacity that has been demonstrated to be compromised following the traumatic stress response. In juxtaposition, Matsuo, Taneichi, and Matsumoto (2003) found that some regions may compensate for functional deficits in other regions and mask the effects of PTSD on functioning. Thus, similar to the debate in the visuospatial traumatic stress response literature, language differences have not been parceled out from attention and executive functioning to draw conclusive inference as to the affects of the traumatic stress response on language functioning in adults. Also similar to the visuospatial literature, Beers and DeBellis (2002) found no differences between the language functioning of maltreated children with PTSD and socio-demographically matched, non-maltreated controls on the Clinical Evaluations of Language Fundamentals Concepts and Directions or WISC-III Vocabulary subtest.

\subsection{Motor functioning}

Motor functioning refers to an individual's ability to execute intentional motor tasks and inhibit unintentional motor tasks. Motor functioning is not hypothesized to be affected by the traumatic stress response. Similar to language functioning, researching motor functioning following traumatic stress is valuable to exploration of the discriminant validity of the traumatic stress response hypothesis. Also similar to the language functioning literature, few studies have explored motor functioning following trauma in adults and no studies have sampled children or adolescents. In general, motor functioning was found to not be affected following PTSD (Gurvits, Lasko, et al., 2002, Gurvits et al., 2000, 2002a, 2002b; Sullivan et al., 2003). However, Vasterling and Brailey (2005) caution that executive functioning impairments resulting from PTSD can masquerade as motor functioning deficits. Similarly, motor tasks that require executive functioning are affected by PTSD (e.g., Gurvits et al., 2000, 1993). In addition to executive functioning confounds, substance use, head injury, and presence of childhood ADHD diagnoses have been found to obfuscate correlations between PTSD and motor functioning deficits (Gurvits et al., 2000, 2002a, 2002b). Thus, the literature supports executive functioning deficits consistent with those hypothesized by the traumatic stress response while excluding motor functioning deficits, which is also consistent with the traumatic stress response.

\subsection{Conclusions and future research directions}

The traumatic stress response is a comprehensive term for an individual's response to a stressor that alters their ability to respond to stress. It encompasses the context of the individual's environment, the nature of the traumatic event, the resultant neurochemical cascade within the brain, and the changes in the individual's functioning following that neurochemical cascade. When developmental considerations are taken into account, the traumatic stress response is an experience outside the average expectable environment that has the potential to alter an individual's developmental trajectory. While adults are susceptible to effects of neuroendocrine dysregulation of the HPAaxis, prefrontal cortex, and limbic system (e.g., Southwick, Rasmusson, Barron, \& Arnsten, 2005), children are also susceptible to effects on prefrontal cortex volume (e.g., Reichert et al., 2006), corpus callosum volume (e.g., Teicher et al., 2004), and cortisol dysregulation (e.g., Cicchetti\& Rogosch, 2001a, 2001b) . The occurrence of traumatic events during childhood can alter the developmental trajectory through prevention of experience-expectant phenomena (e.g., impairing myelination, e.g., Teicher, et al., 2004) or experience-dependent phenomena (e.g., preventing integration of environmental stimuli to reinforce children's seeking of positive adult interactions, e.g., Ford, 2005). Alterations of the developmental trajectory of children can lead to emotional, behavioral, and cognitive difficulties (e.g., Kendall- Tackett, Williams, \& Finkelhor, 1993). Neuropsychological research has linked neuropsychological deficits in cognitive capacity (e.g., Jones et al., 2004), attention (e.g., Porter, et al., 2005), and executive functioning (e.g., De Bellis, 2005) in children to the traumatic stress response. Further, these deficits correlate with regions of the brain af fected by the traumatic stress response that also correlate with clinical presentation of symptoms (e.g., Schwartz \& Perry, 1994).

Based on the review of the literature, the following are important considerations for future research. For one, future research should be careful to be more inclusive, rather than exclusive with subject recruitment. As such, traumatic experiences should determine inclusion criteria, with abuse experiences and individual responses examined as continuous, rather than categorical variables of diagnosis-based grouping. Another methodological consideration is more robust assessment of children's functioning. Future research of the traumatic stress response in maltreated children should include assessments of cognitive, emotional, and behavioral functioning of participants. As such, future research models should assess for and address ambiguous symptom presentation of behavior dysregulation that could be indicative of the traumatic stress response. Finally, future research should consider replicating or approximating adult studies with child and adolescent samples.

As a footnote to the literature review, it is important to remember the clinical implications of research of the traumatic stress response in maltreated children. Recently, in the APA's Div. 37 Child Maltreatment Newsletter (2008), MacDonald called attention to the need for more comprehensive neuropsychological evaluations of maltreated children. She cited proper assessment of the neuropsychological functioning af fects of PTSD as crucial to best practice in treating maltreated children 
across multiple settings, such as school and home. Other researchers agree that the traumatic stress response following child maltreatment will not only affect emotional functioning, but cognitive and neuropsychological functioning in school and on a broader basis (Cook-Cotton, 2004; Danckwerts \& Leathem, 2003; De Bellis et al., 2005; Horner \& Hamner, 2002). Several researchers point to the potential misdiagnosis of ADHD in maltreated children (e.g., Disseth, 2005; Ford, 2005; Salmon \& Bryant, 2002; Weber \& Reynolds, 2004) due to the overlap in neuropsychological symptoms presentation, reiterating the need for comprehensive evaluations. Thus, research into the neuropsychological effects of the traumatic stress response will benefit clinicians in the development of comprehensive, but efficient evaluations for maltreated children such that interventions can be implemented in all environments.

\section{References}

Altemus, M., Dhabhar, F. S., \& Yang, R. (2006). Immune function in PTSD. Annals of the New York Academy of Sciences, 1071, 167-183.

American Psychiatric Association (2003). Diagnostic and statistical manual of mental disorders (4th ed). Washington, DC: Author.

Barrett, D. H., Green, M. L., Morris, R., Giles, W. H., \& Croft, J. B. (1996). Cognitive functioning and posttraumatic stress disorder. The American Journal of Psychiatry, 153, 1492-1494.

Beckham, J. C., Crawford, A. L., \& Feldman, M. E. (1998). Trail making test performance in Vietnam combat veterans with and without posttraumatic stress disorder. Journal of Traumatic Stress, 11, 811-819.

Beers, S. R., \& DeBellis, M. D. (2002). Neuropsychological function in children with maltreatment-related posttraumatic stress disorder. The American Journal of Psychiatry, 159, 483-486.

Bevans, K., Cerebone, A. B., \& Overstreet, S. (2005). Advances and future directions in the study of children's neurobiological responses to trauma and violence exposure. Journal of Interpersonal Violence, 20, 418-425.

Bifulco, A., Moran, P. M., Baines, R., Bunn, R., \& Stanford, K. (2002). Exploring psychological abuse in childhood: II. Association with other abuse and adult depression. Bulletin of the Menninger Clinic, 66, 241-258.

Bonne, O., Brandes, D., Gilboa, A., Gomori, J. M., Shenton, M. E., Pitman, R. K., et al. (2001). Longitudinal MRI study of hippocampal volume in trauma survivors with PTSD. The American Journal of Psychiatry, 158, 1248-1251.

Brandes, D., Ben-Schachar, G., Gilboa, A., Bonne, O., Freedman, S., \& Shalev, A. Y. (2002). PTSD symptoms and cognitive performance in recent trauma survivors. Psychiatry Research, 110, 231-238.

Bremner, J. D., Narayan, M., Staib, L. H., Southwick, S. M., McGlashan, T., \& Charney, D. S. (1999). Neural correlates of memories of childhood sexual abuse in women with and without posttraumatic stress disorder. The American Journal of Psychiatry, 156, 1787-1795.

Bremner, J. D., Randall, P., Scott, T. M., Capelli, S., Delaney, R., McCarthy, G., \& Charney, D. S. (1995). Deficits in short-term memory in adult survivors of childhood abuse. Psychiatry Research, 59, 97-107.

Bremner, J. D., Scott, T. M., Delany, R. C., Southwick, S. M., Mason, J. W., Johnson, D. R., et al. (1993). Deficits in short-term memory in post-traumatic stress disorder. The American Journal of Psychiatry, 150, 1015-1019.

Bremner, J. D., Vythilingham, M., Vermetten, E., Southwick, S. M., McGlasehan, T., Nazeer, A., et al. (2003). MRI and PET study of deficits in hippocampal structure in women with childhood sexual abuse and posttraumatic stress disorder. The American Journal of Psychiatry, 106, 924-932.

Bustamante, V., Mellman, T. A., \& David, D. (2001). Cognitive functioning and the early development of PTSD. Journal of Traumatic Stress, 14, 791-797.

Carter, L. S., Weithorn, L. A., \& Behrman, R. E. (1999). Domestic violence and children: Analysis and recommendations. The Future of Children, 9(3), 4-20.

Cicchetti, D. (2007). Intervention and policy implications of research on neurobiological functioning in maltreated children. In J. Aber, S. Bishop-Josef, S. Jones, K. McLearn, \& D. Phillips (Eds.), Child development and social policy: Knowledge for action (pp. 167-184). Washington, DC: American Psychological Association.

Cicchetti, D., \& Lynch, M. (1993). Toward an ecological/transactional model of community violence and child maltreatment: Consequences for children's development. Psychiatry: Interpersonal and Biological Processes, 56(1), 96-118.

Cicchetti, D., \& Rogosch, F. A. (2001a). The impact of child maltreatment and psychopathology on neuroendocrine functioning. Development and Psychopathology, 13, 783-804.

Cicchetti, D., \& Rogosch, F. A. (2001b). Diverse patterns of neuroendocrine activity in maltreated children. Development and Psychopathology, 13(3), 677-693.

Cicchetti, D., \& Toth, S. L. (2005). Child maltreatment. Annual Review of Clinical Psychology, 1, 409-438.
Cohen, J. A., Perel, J. M., De Bellis, M. D., Friedman, M. J., \& Putnam, F. W. (2002) Treating traumatizes children, clinical implications of the psychobiology of posttraumatic stress disorder. Trauma,Violence \& Abuse, 3, 91-108.

Cohen, H., \& Zohar, J. (2004). An animal model of posttraumatic stress disorder, the use of cut-off behavioral criteria. Annals of the New York Academy of Sciences, 1032, $167-178$.

Cook-Cotton, C. (2004). Childhood Posttraumatic Stress Disorder: Diagnosis, treatment, and school reintegration. School Psychology Review, 33, 127-139.

Danckwerts, A., \& Leathem, J. (2003). Questioning the link between PTSD and cognitive dysfunction. Neuropsychological Review, 13, 221-235.

De Bellis, M. D. (2005). The psychobiology of neglect. Child Maltreatment, 10, $150-172$.

De Bellis, M. D., Hall, J., Boring, A. M., Frustaci, K., \& Moritz, G. (2001). A pilot longitudinal study of hippocampal volume in pediatric maltreated-related posttraumatic stress disorder. Society of Biological Psychiatry, 50, 305-309.

De Bellis, M. D., Hooper, S. R., \& Sapia, J. L. (2005). Early trauma exposure and the brain. In J. J. Vasterling, \& C. R. Brewin (Eds.), Neuropsychology of PTSD, biological, cognitive, and clinical perspectives (pp. 153-177). New York: Guilford Press.

Delahanty, D. L., \& Nugent, N. R. (2006). Predicting PTSD prospectively based on prior trauma history and immediate biological responses. Annals of the New York Academy of Sciences, 1071, 27-40.

Delahanty, D. L., Nugent, N. R., Christopher, C. H., \& Walsh, M. (2005). Initial urinary epinephrine and cortisol levels predict acute PTSD symptoms in child trauma victims. Psychoneuroendocrinology, 30, 121-128.

Delgado, M. R., Olsson, A., \& Phelps, E. A. (2006). Extending animal models of fear conditioning to humans. Biological Psychology, 73, 39-48.

Disseth, T. H. (2005). Dissociation in children and adolescents as reaction to traumaOn overview of conceptual issues and neurobiological factors. Nordic Journal of $P_{s y-}$ chiatry, 59, 79-91.

Dozier, M., Manni, M., Gordon, M. K., Peloso, E., Gunnar, M. R., Stovall-McClough, K. C., et al. (2006). Foster children's diurnal production of cortisol: an exploratory study. Child Maltreatment, 11, 189-197.

Fantuzzo, J. W., \& Mohr, W. K. (1999). Prevalence and effects of child exposure to domestic violence. The Future of Children, 9, 21-32.

Ford, J. D. (2005). Treatment implications of altered affect regulation and information processing following child maltreatment. Psychiatric Annals, 35, 410-419.

Frewen, P. A., \& Lanius, R. A. (2006). Towards a psychobiology of posttraumatic selfdysregulation. Annals of the New York Academy of Sciences, 1071, 110-124.

Gabbay, V., Oatis, M. D., Silva, R. R., \& Hisrch, G. S. (2004). Epidemiological aspects of PTSD in children and adolescents. In Raul R. Silva (Ed.), Posttraumatic stress disorders in children and adolescents: Handbook (pp. 1-17). New York: Norton.

Gil, T., Calev, A., \& Greenberg, D. (1990). Cognitive functioning in Post-Traumatic Stress Disorder. Journal of Traumatic Stress, 3(1), 29-45.

Glaser, D. (2000). Child abuse and neglect. Journal of Child Psychology and Psychiatry, $41,97-116$.

Golier, J., Yehuda, R., Cornblatt, B., Harvey, P., Gerber, D., \& Levengood, R. (1997). Sustained attention in combat-related posttraumatic stress disorder. Integrative Physiological and Behavioral Science, 32, 52-61.

Greenough, W. T., Black, J. E., \& Wallace, C. S. (1987). Experience and brain development. Child Development, 58, 539-559.

Gurvits, T. V., Carson, M. A., Metzger, L., Croteau, H. B., Lasko, N. B., Orr, S. P., et al. (2002). Absence of selected neurological soft signs in Vietnam nurse veterans with posttraumatic stress disorder. Psychiatry Research, 110, 81-85.

Gurvits, T. V., Gilbertson, M. W., Lasko, N. B., Tarham, A. S., Simeon, D., Macklin, M L., et al. (2000). Neurological soft signs in chronic posttraumatic stress disorder. Archives of General Psychiatry, 57, 181-186.

Gurvits, T. V., Lasko, N. B., Repak, A. L., Metger, L. J., Orr, S. P., \& Pitman, R. K. (2002). Performance on visuospatial copying tasks in individuals with posttraumatic stress disorder. Psychiatry Research, 112, 263-268.

Gurvits, T. V., Lasko, N. B., \& Schachter, S. C. (1993). Neurological status of Vietnam veterans with chronic posttraumatic stress disorder. The Journal of Neuropsychiatry and Clinical Neurosciences, 5(2), 183-188.

Hart, J., Gunnar, M., \& Cicchetti, D. (1996). Altered neuroendocrine activity in maltreated children relates to symptoms of depression. Development and Psychopathology, 8, 201-214.

Harvey, B. H., Bothman, T., Nel, A., Wegener, G., \& Stein, D. J. (2005). Involvement of the NMDA receptor, NO-cyclic GMP and nuclear factor K-B in an animal model of repeated trauma. Human Psychopharmacology Clinical Experiments, 20, $367-373$.

Harvey, B. H., Brand, L., Jeeva, Z., \& Stein, D. J. (2006). Cortical/hippocampal monoamines, HPA-axis changes and aversive behavior following stress and restress in an animal model of post-traumatic stress disorder. Physiology \& Behavior, $87,881-890$.

Harvey, B. H., Oosthuizen, F., Brand, L., Wegner, G., \& Stein, D. J. (2004). Stress-restress evokes sustained iNOS activity and altered GABA levels and NMDA receptors in rat hippocampus. Psychopharmacology, 175, 494-502. 
Heim, C., \& Nemeroff, C. B. (2001). The role of childhood trauma in the neurobiology of mood and anxiety disorders: Preclinical and clinical studies. Society of Biological Psychiatry, 49, 1023-1039.

Horner, M. D., \& Hamner, M. B. (2002). Neurocognitive functioning in posttraumatic stress disorder. Neuropsychological Review, 12, 15-29.

Hulme, P. A., \& Agrawal, S. (2004). Patterns of childhood sexual abuse and their characteristics to other childhood abuse and adult health. Journal of Interpersonal Violence, 19, 389-405.

Jenkins, M. A., Langlais, P. J., Delis, D., \& Cohen, R. A. (2000). Attentional dysfunction associated with Posttraumatic Stress Disorder among rape survivors. The Clinical Neuropsychologist, 14, 7-12

Jones, D. A., Trudinger, P., \& Crawford, M. (2004). Intelligence and achievement of children referred following sexual abuse. Journal of Paediatric Child Health, 40, $455-460$.

Kendall-Tackett, K. A., Williams, L. M., \& Finkelhor, D. (1993). Impact of sexual abuse on children: A review and synthesis of recent empirical studies. Psychological Bulletin, 113, 164-180.

King, J. A., Mandansky, D., King, S., Fletcher, K. E., \& Brewer, J. (2001). Early sexual abuse and low cortisol. Psychiatry and Clinical Neurosciences, 55, 71-74.

Koenen, K. C., Driver, K. L., Oscar-Berman, M., Wolfe, J., Folsom, S., Huang, M. T., et al. (2001). Measures of prefrontal system dysfunction in posttraumatic stress disorder. Brain and Cognition, 45(1), 64-78.

Liberzon, I., \& Martis, B. (2006). Neuroimaging studies of emotional response in PTSD. Annals of the New York Academy of Sciences, 1071, 87-109.

Linkowski, P. (2003). Neuroendocrine profiles in mood disorders. The International Journal of Neuropsychopharmacology, 6(2), 191-197.

Litz, B. T., Weathers, F. W., Monaco, V., Herman, D. S., Wulfsohn, M., Marx, B., et al. (1996). Attention, memory, arousal, and memory in posttraumatic stress disorder. Journal of Traumatic Stress, 9, 497-520.

MacDonald, H. Z. (2008, Winter). Neuropsychological assessment and functioning in children with Posttraumatic Stress Disorder. Section on Child Maltreatment, Division 37 (pp. 6-7). : American Psychological Association.

Macklin, M. L., Metzger, L. J., Litz, B. T., McNally, R. J., Lasko, N. B., Orr, S. P., et al. (1998). Lower precombat intelligence is a risk factor for posttraumatic stress disorder. Journal of Consulting and Clinical Psychology, 66, 323-326.

Manly, J. T. (2005). Advances in research definitions of child maltreatment. Child Abuse \& Neglect, 29, 425-439.

Matsuo, K., Taneichi, K., \& Matsumoto, A. (2003). Hypoactivation of the prefrontal cortex during verbal fluency test in PTSD: A near-infrared spectroscopy study. Psychiatry Research: Neuroimaging, 124(1), 1-10.

McFarlane, A. C., Weber, D. L., \& Clark, C. R. (1993). Abnormal stimulus processing in post-traumatic stress disorder. Biological Psychiatry, 5, 817-826.

McNally, R. J., \& Shin, L. M. (1995). Association of intelligence with severity of posttraumatic stress disorder symptoms in Vietnam combat veterans. The American Journal of Psychiatry, 152, 936-938.

Moradi, A. R., Neshat Doost, H. T., Taghavi, M. R., Yule, W., \& Dalgleish, T. (1999). Everyday memory deficits in children and adolescents with PTSD: Performance on the Rivermead Behavioural Memory Test. Journal of Child Psychology and Psychiatry, 40, 357-361.

Phelps, E. A. (2004). Human emotion and memory: Interactions of the amygdala and hippocampal complex. Current Opinion in Neurobiology, 14, 198-202.

Porter, C., Lawson, J. S., \& Bigler, E. D. (2005). Neurobehavioral sequelae of child sexual abuse. Child Neuropsychology, 11, 203-220.

Raskin, S. A. (1997). The relationship between sexual abuse and brain injury. Brain Injury, 11, 587-603.

Reichert, K. A., Carrion, V. G., Karchemshkiy, A., \& Reiss, A. L. (2006). Regional differences of the prefrontal cortex in pediatric PTSD: An MRI study. Depression and Anxiety, 23, 17-25.

Sadeh, A., Hayden, R. M., McGuire, J. P. D., Sachs, Henry, \& Civita, R. (1994). Somatic, cognitive, and emotional characteristics of abused children in a psychiatric hospital. Child Psychiatry and Human Development, 24, 191-200.

Saigh, P. A., Yasik, A. E., Oberfield, R. A., Halamandaris, P. V., \& Bremner, J. D. (2006). The intellectual performance of traumatized children and adolescents with or without posttraumatic stress disorder. Journal of Abnormal Psychology, 115(2), $332-340$.

Salmon, K., \& Bryant, R. A. (2002). Posttraumatic stress disorder in children: The influences of developmental factors. Clinical Psychology Review, 22, 163-188.

Schwartz, E. D., \& Perry, B. D. (1994). The post-traumatic stress response in children and adolescents. The Psychiatric Clinics of North America, 17, 311-326.

Semple, W. E., Goyer, P. F., McCormick, R., Compton-Toth, B., Morris, E., Donovan, B., et al. (1996). Attention and regional cerebral blood flow in posttraumatic stress disorder patients with substance abuse histories. Psychiatry Research: Neuroimaging, 67, 17-28.

Shekhar, A., Truitt, W., Rainnie, D., \& Sajdyk, T. (2005). Role of stress, corticotrophinreleasing factor and amygdala plasticity in chronic anxiety. Stress, 8, 209-219.
Shimamura, A. P. (2002). Memory retrieval and executive control processes. In D. T. Stuss, \& R. T. Knight (Eds.), Principles of frontal lobe function (pp. 210-220). New York: Oxford University Press.

Shin, L. M., Rauch, S. L., \& Pitman, R. K. (2006). Amygdala, medial prefrontal cortex, and hippocampal function in PTSD. Annals of the New York Academy of Sciences, 1071, 67-97.

Silverman, A. B., Reinherz, H. Z., \& Giaconia, R. M. (1996). The long-term sequelae of child and adolescent abuse: A longitudinal community study. Child Abuse \& Neglect, 20, 709-723.

Southwick, S. M., Rasmusson, A., Barron, J., \& Arnsten, A. (2005). Neurobiological and neurocognitive alterations in PTSD, a focus on norepinephrine, serotonin, and the hypothalamic-pituitary-adrenal axis. In J. J. Vasterling, \& C. R. Brewin (Eds.), Neuropsychology of PTSD, biological, cognitive, and clinical perspectives (pp. 27-58). New York: Guilford Press.

Sullivan, K., Krengel, M., Proctor, S. P., Devine, S., Heeren, T., \& White, R. F. (2003). Cognitive functioning in treatment-seeking Gulf War veterans: Pyridostigmine bromide use and PTSD. Journal of Psychopathology and Behavioral Assessment, 25, 95-103.

Teicher, M. H. (2002). Scars that won't heal: The neurobiology of child abuse. Scientific American, 286, 68-76.

Teicher, M. H., Andersen, S. L., Polcari, A., Andersen, C. M., \& Navalta, C. P. (2002). Developmental neurobiology of childhood stress and trauma. 2002. The Psychiatric Clinics of North America, 25, 397-426.

Teicher, M. H., Andersen, S. L., Polcari, A., Andersen, C. M., Navalta, C. P., \& Kim, D. M. (2003). The neurobiological consequences of early stress and childhood maltreatment. Neuroscience and Biobehavioral Reviews, 27, 33-44.

Teicher, M. H., Dumont, N. L., Ito, Y., Vaituzis, C., Giedd, J. N., \& Andersen, S. L. (2004). Child neglect is associated with reduced corpus callosum area. Biological Psychiatry, 56, 80-85.

Teicher, M. H., Tomodoa, A., \& Andersen, S. L. (2006). Neurobiological consequences of early stress and childhood maltreatment: Are results from human and animal studies comparable? Annals of the New York Academy of Sciences, 1071, 313-323.

U.S. Department of Health and Human Services, Administration on Children, Youth and Families (2007). Child Maltreatment 2005. Washington, DC: Government Printing Office.

Uddo, M., Vasterling, J. J., Brailey, K., \& Sutker, P. B. (1993). Memory and attention in combat-related post-traumatic stress disorder (PTSD). Journal of Psychopathology and Behavioral Assessment, 15, 43-52.

Vasterling, J. J., \& Brailey, K. (2005). Neuropsychological findings in adults with PTSD. In J. J. Vasterling, \& C. R. Brewin (Eds.), Neuropsychology of PTSD, biological, cognitive, and clinical perspectives (pp. 178-207). New York: Guilford Press.

Vasterling, J. J., Brailey, K., Constans, J. I., Borges, A., \& Sutker, P. B. (1997). Assess ment of intellectual resources in Gulf War veterans: Relationship to PTSD. Assessment, 4, 51-59.

Vasterling, J. J., Brailey, K., Constans, J. I., \& Sutker, P. B. (1998). Attention and mem ory dysfunction in posttraumatic stress disorder. Neuropsychology, 12, 125-133.

Vasterling, J. J., Duke, L. M., Brailey, K., Constans, J. I., Allain, A. N., Jr., \& Sutker, P. B. (2002). Attention, learning, and memory performances and intellectual resources in Vietnam veterans: PTSD and no disorder comparisons. Neuropsychology, $16,5-14$

Vasterling, J. J., Rogers, C., \& Kaplan, E. (2000). Qualitative Block Design analyses in posttraumatic stress disorder. Assessment, 7, 217-226.

Vermetten, E., \& Bremner, J. D. (2002a). Circuits and systems in stress. I. Preclinical studies. Depression and Anxiety, 15, 126-147.

Vermetten, E., \& Bremner, J. D. (2002b). Circuits and systems in stress. II. Applications to neurobiology and treatment in posttraumatic stress disorder. Depression and Anxiety, 16, 14-38.

Watts-English, T., Fortson, B. L., Gibler, N., Hooper, S. R., \& De Bellis, M. D. (2006). The psychobiology of maltreatment in children. Journal of Social Issues, 62, $717-736$.

Weber, D. A., \& Reynolds, C. R. (2004). Clinical perspectives on neurobiological effects of psychological trauma. Neuropsychology Review, 14(2), 115-129.

Weems, C. F., Saltzman, K. M., Reiss, A. L., \& Carrion, V. G. (2003). A prospective test of the association between hyperarousal and emotional numbing in youth with a history of traumatic stress. Journal of Clinical Child and Adolescent Psychology, 32, $166-171$.

Yasik, A. E., Saigh, P. A., Oberfield, R. A., \& Halamandaris, P. V. (2007). Posttraumatic stress disorder: Memory and learning performance in children and adolescents. $\mathrm{Bi}-$ ological Psychiatry, 61, 382-388.

Yehuda, R., Keefe, R. S. E., Harvey, P. D., Levengood, R. A., Gerber, D. K., Geni, J., et al. (1995). Learning and memory in combat veterans with posttraumatic stress disorder. The American Journal of Psychiatry, 152, 137-139.

Zillmer, E. A., Spiers, M. V., \& Culbertson, W. C. (2008). Memory, attention, emotion, and executive functioning. Principles of neuropsychology (pp. 225-265). (Second edition). Belmont, CA: Thompson Wadsworth. 
